\title{
Formulation and Evaluation of Apremilast Co-crystals Loaded in Gel
}

\author{
Syed Fahid Ali*, Ayesha Farhath Fathima, Dr. Niranjan Panda \\ Department of Pharmaceutics, Anwarul Uloom College of Pharmacy, New Mallepally, Hyderabad, Telangana, India. \\ *Corresponding author's E-mail: sfahad4789@gmail.com
}

Received: 08-11-2021; Revised: 16-01-2022; Accepted: 25-01-2022; Published on: 15-02-2022.

\begin{abstract}
Apremilast has low solubility and irritant effect in GIT can cause ulcerative colitis with bleeding. In this study, pharmaceutical cocrystals were designed to efficiently deliver Apremilast (APR) by topical administration to overcome this issue. Cocrystallization of drug with conformer is an immense approach used to explore the physicochemical properties of drug. Formulation and evaluation of APR co-crystals by solvent evaporation method for solubility enhancement were the objective of the current research. All the prepared formulations were evaluated by powder Fourier-transform infrared spectroscopy (FTIR), differential scanning calorimetry (DSC), dissolution, and solubility studies. Dissolution and solubility studies of the formulations confirmed that solubility enhanced as compared to the solubility of the available market drugs. From all these studies, it can be concluded that the co-crystallization technique enhanced the solubility of APR by using the solvent evaporation method. The cocrystals of APR were prepared in 1:1 molar ratio with urea. APR cocrystals showed the improvement in solubility and dissolution as compared to pure APR. The formation of cocrystals was confirmed from change in endothermic peak of DSC and from shifting of FTIR spectra of cocrystals. The topical gel of APR cocrystals was formulated using Carbapol-940 and hydroxypropyl methylcellulose (HPMC) as a gelling agent. The cocrystals with altered physicochemical properties of APR were prepared with Urea and formulated as a topical gel to overcome the problems related to oral administration. F2 formulation was found to be optimized batch and selected variables show a significant effect on the responses that are drug release and spread ability.
\end{abstract}

Keywords: Apremilast, Urea, Solvent evaporation, Solubility, Co-crystals, Gel.

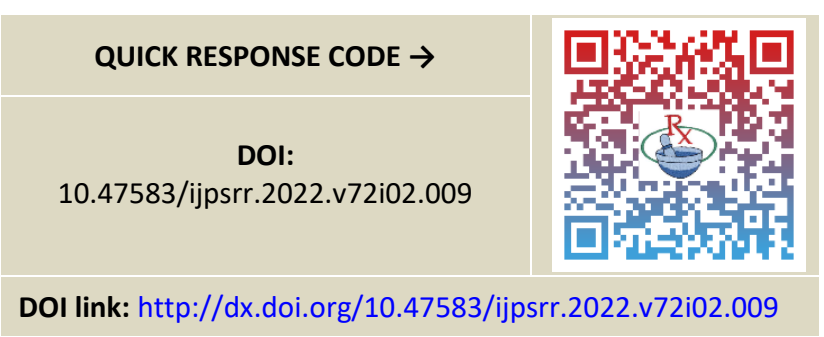

\section{INTRODUCTION}

soriasis is an immune-mediated, genetic disorder manifesting within the skin or joints or both. The high physical burden of disease isn't so well understood by scientists but could be associated with symptoms like itching or burning sensations. ${ }^{1}$ Symptoms repeatedly reported by patients include pain, itch, and bleeding. ${ }^{2}$ Individuals with psoriasis are at an increased risk of developing other chronic and high health diseases. These comorbid diseases include atrophic arthritis, metabolic syndrome or components of the syndrome, cardiovascular disorders, and variety of other diseases like anxiety and depression, non-alcoholic disease, Crohn's disease, and lymphoma. ${ }^{3,4}$ Topical therapies like glucocorticosteroids, vitamin $D$ derivatives, or combinations of both are usually sufficient to manage the mild disease. Results from a recent meta-analysis ${ }^{4}$ showed that a mixture of corticosteroids and vitamin D3 was the foremost effective treatment for the scalp. Practicability (time needed to use treatment), convenience, and adverse effects like skin irritation limit the utilization of topical drugs. Established systemic drugs for the treatment of psoriasis include methotrexate, cyclosporin, acitretin, and in some countries acid esters. Additionally, the oral phosphodiesterase-4 inhibitor apremilast has been approved within the USA and Europe.

Apremilast (Otezla, Celgene Corporation, Summit, NJ) was approved by the US Food and Drug Administration (FDA) in 2014 and by the European Commission in 2015 for treatment of psoriasis and psoriatic arthritis. ${ }^{5,6}$ It specifically inhibits phosphodiesterase ${ }^{4}$.

\section{Cocrystals}

Cocrystals are multicomponent molecular crystals where all components are at a stoichiometric ratio and comprise of two or more chemically different molecules includes modification of drugs to alter physical properties of a drug, especially a drug's solubility without altering its pharmacology effect. $7,8,9$

Co-crystals can be prepared by solvent and solid based methods. The solvent-based methods involve slurry conversion solvent evaporation, cooling crystallization and precipitation. The solid based methods involve net grinding; solvent-assisted grinding and sonication (applied to either to wet or dry solid mixtures) 80 to $85^{\circ} \mathrm{C}$.

Solvent evaporation is the most convenient method in the case of crystallization. In this technique, the material is mixed with the common solvent and evaporated 
completely. In the evaporation stage, the solution of molecules is expected to undergo various hydrogen bonding reactions.

Topical drug delivery offers several advantages compared to oral administration. Without entering the bloodstream, the active ingredient can reach the site of inflammation, increase in the concentration of the drug on the skin, which helps in increasing the amount of the drug in the formulation without fearing from toxicity or GIT problems. It is also possible to avoid systemic adverse effects in this way. Besides, by targeting the drug directly to the affected area, the first-pass effect can be reduced..$^{10}$

The current study is conducted to formulate, and evaluate the APR cocrystal loaded with topical gel. Since the APR has two major problems when administered orally; first, it has low solubility and irritant effect in GIT can cause ulcerative colitis with bleeding.

\section{MATERIALS AND METHODS}

\section{Materials}

APR was obtained as gift sample from Mylan Laboratories Limited (Unit-7), Telangana, India. Urea, methanol and all other chemicals were obtained from Hyderabad. Double distilled water and analytical grade quality solvents were used throughout the research work.

\section{Method}

\section{Formulation of cocrystal}

APR cocrystals were prepared using the solvent evaporation method. Accurately weighed APR and conformer urea in 1:1 molar ratio was dissolved in an appropriate quantity of methanol as a solvent. The prepared mixture was heated on a hot plate till clear solutions were obtained and allow standing for evaporation of solvent at room temperature. The fine crystals were obtained after a few days which were collected, dried, and stored in an airtight container until further use. ${ }^{11}$

\section{Preparation of APR Cocrystal loaded gel}

Accurately weighed quantity of Carbopol 940 and HPMC was dissolved in $10 \mathrm{ml}$ of distilled water $\left(70^{\circ} \mathrm{C}\right)$ in beaker $A$. In another beaker B, $100 \mathrm{mg}$ of APR cocrystal was dissolved in $8 \mathrm{ml}$ of glycerin. Then, $2 \mathrm{ml}$ of $10 \% \mathrm{NaoH}$ and sufficient quantity of methyl paraben was added to a mixture containing APR cocrystal. Finally, beaker B containing solution was added into the beaker A. Properly mixed the above mixture and stirred well using mechanical stirrer to get a homogeneous mixture. Six different formulations were designed by varying the concentration of carbopol 940 and HPMC given in Table 1.

Table 1: Formulation of Apremilast cocrystal loaded gel

\begin{tabular}{|c|c|c|c|c|c|c|}
\hline INGREDIENTS & $\mathbf{F}_{\mathbf{1}}$ & $\mathbf{F}_{\mathbf{2}}$ & $\mathbf{F}_{\mathbf{3}}$ & $\mathbf{F}_{\mathbf{4}}$ & $\mathbf{F}_{\mathbf{5}}$ & $\mathbf{F}_{\mathbf{6}}$ \\
\hline Apremilast & 5 & 5 & 5 & 5 & 5 & 5 \\
\hline Urea & 5 & 5 & 5 & 5 & 5 & 5 \\
\hline Carbopol 940 & 0.5 & 1.25 & 0.2 & 0.5 & 0.7 & 0.7 \\
\hline HPMC K4M & 0.5 & 1.25 & 0.5 & 0.2 & 0.7 & 0.5 \\
\hline 10\% NaoH & 2 & 3 & 2 & 3 & 5 & 4 \\
\hline Glycerin & 30 & 30 & 30 & 30 & 30 & 30 \\
\hline Methyl Paraben & Q.S & Q.S & Q.S & Q.S & Q.S & Q.S \\
\hline Methanol & 40 & 40 & 40 & 40 & 40 & 40 \\
\hline
\end{tabular}

\section{Characterization of cocrystal}

\section{Physical appearance}

Prepared APR cocrystals were visually characterized to study its color, odor, and texture.

\section{Differential Scanning Calorimetry (DSC)}

Differential Scanning Calorimetry, or DSC, is a thermal analysis technique that looks at how a material's heat capacity (Cp) is changed by temperature. A sample of known mass is heated or cooled and the changes in its heat capacity are tracked as changes in the heat flow. This allows the detection of transitions such as melts, glass transitions, phase changes, and curing. Because of this flexibility, since most materials exhibit some sort of transitions, DSC is used in many industries, including pharmaceuticals, polymers, food, paper, printing, manufacturing, agriculture, semiconductors, and electronics. $^{12}$

\section{Fourier-transform infrared (FTIR) spectroscopy study}

Fourier transform infrared (FTIR) spectroscopy probes the vibrational properties of amino acids and cofactors, which are sensitive to minute structural changes. The APR and APR cocrystals FTIR spectra were obtained using FTIR spectrophotometer. The samples were mixed with potassium bromide in 1:1 molar ratio and compressed into a disc before scanning between 4000 and $400 \mathrm{~cm}-1$ with a resolution of $4 \mathrm{~cm}-1$ the IR spectroscopy was used to determine the interaction between drug and conformer. ${ }^{13}$

\section{Drug content}

Weighed quantity $(10 \mathrm{mg}$ ) of prepared APR cocrystals was taken and dissolved in $100 \mathrm{ml}$ methanol. Then, the solution was ultrasonicated for $15 \mathrm{~min}$ to get a uniform solution. 
After that, the absorbance of the obtained solution was measured using an ultraviolet (UV)-visible spectrophotometer at $230 \mathrm{~nm} \cdot{ }^{14}$

\section{Saturated solubility study}

Accurately weighed dried APR cocrystal equivalent to APR $100 \mathrm{mg}$ of reconstituted with $50 \mathrm{ml}$ of distilled water in a conical flask plugged with cotton. It was shaken for $48 \mathrm{~h}$ using orbital shaker. The samples were collected after the specified time interval, and it is filtered and analyzed. The diluted samples were analyzed using UV spectrophotometer. The same procedure was repeated for pure APR and physical mixture of APR:Urea (1:1). ${ }^{15}$

\section{In vitro dissolution study of cocrystal}

The dissolution studies (\%) were carried out in $\mathrm{pH} 6.8$ phosphate buffer solution $(900 \mathrm{ml})$ for $60 \mathrm{~min}$ at $37 \pm 0.5$ and $50 \mathrm{rpm}$ using United States Pharmacopeia (USP) type II dissolution test apparatus. The pure drug APR and APR cocrystal equivalent to $20 \mathrm{mg}$ of drug were used for the study. Five milliliters of samples were withdrawn after a specified time interval and immediately replaced with an equal volume of fresh dissolution medium. The sample was filtered using Whatman filter paper. Later suitable dilutions of the sample were done and analyzed using a UV-visible spectrophotometer at $230 \mathrm{~nm} .{ }^{16}$

\section{Characterization of gel loaded with APR}

\section{Physical appearance}

The formulated gels were inspected visually for its color, consistency, and appearance.

\section{Homogeneity}

The formulated gels were checked for its homogeneity by visual inspection after filled into a suitable container. The gels were observed for their appearance and presence of any particulate matter. ${ }^{59}$

\section{pH determination}

$\mathrm{pH}$ of the formulated gels was determined using digital $\mathrm{pH}$ meter and observed readings were noted.

\section{Spread ability}

The spread ability $(\mathrm{cm})$ of the gel formulations was determined by placing accurately weighed $1 \mathrm{~g}$ of gel between two horizontal glass plates and $500 \mathrm{~g}$ of weight applied over the plate for $1 \mathrm{~min}$. Later, the spread ability was determined by measuring the diameter of gel spread over the plate in 1 minute.

\section{Viscosity}

The viscosity (cps) of the prepared gels was determined using Brookfield Viscometer. The spindle was rotated at 10 $\mathrm{r} / \mathrm{min}$ and the sample was allowed to settle for $30 \mathrm{~min}$ at temperature $25^{\circ} \mathrm{C}$ before the readings were taken. ${ }^{63}$

\section{In vitro drug release study}

In vitro drug release study (\%) was carried out using fabricated vertical Franz diffusion cell apparatus. The cellophane membrane was used for this study. An accurate amount of gel $(0.5 \mathrm{~g})$ was applied on cellophane membrane. Entire surface of the membrane was in contact with a receptor compartment filled with $20 \mathrm{ml}$ phosphate buffer of pH 6.8 as a diffusion media. The whole assembly was placed on a magnetic stirrer and the solution was stirred continuously at $200 \mathrm{rpm}$ with the temperature maintained at $37 \pm 1^{\circ} \mathrm{C}$. The sample $(1 \mathrm{ml})$ was withdrawn at a specific time interval and replaced with the same volume of fresh phosphate buffer to maintain sink condition. Further suitable dilution of the sample was made and analyzed using a UV-visible spectrophotometer at $230 \mathrm{~nm}$.

\section{Stability studies}

Prepared APR cocrystal loaded formulations were filled in a suitable container and subjected to stability study as per $\mathrm{ICH}$ guidelines. Formulations were kept at $40^{\circ} \mathrm{C} / 75 \% \mathrm{RH}$, $25^{\circ} \mathrm{C} / 60 \% \mathrm{RH}$, and room temperature for 1 month. Samples were evaluated for $\mathrm{pH}$, physical appearance, viscosity, spreadability, and drug release.

\section{RESULTS AND DISCUSSION}

\section{Preformulation study}

\section{Appearance of drug substance}

Prepared APR cocrystals were found to be white in color.

\section{Determination of drug content}

The drug content of the APR cocrystals was found to be $86.3 \%$. The obtained drug content was quite sufficient to the formulation of cocrystals in a suitable dosage form.

\section{DSC}

DSC analysis was used to evaluate the phase transformation during the formation of cocrystals. DSC thermogram of APR in (Fig.1) showed an endothermic peak at $156.45^{\circ}$ corresponding to its reported melting point and the reported melting point of urea was $228.8^{\circ}$. There was a shift in the thermogram observed in the case of APR cocrystal (Fig.2) and the peak was showed at $136^{\circ}$. The non-covalent interaction between the drug and conformer is an indication of the formation of cocrystals. This noncovalent interaction between drug and conformer is occurred due to the formation of a hydrogen bond between the polar functional group. This interaction resulted into the change in the molecular structure of the cocrystals formed which gives a new crystalline form of drug with altered physical properties such as solubility and melting point. 


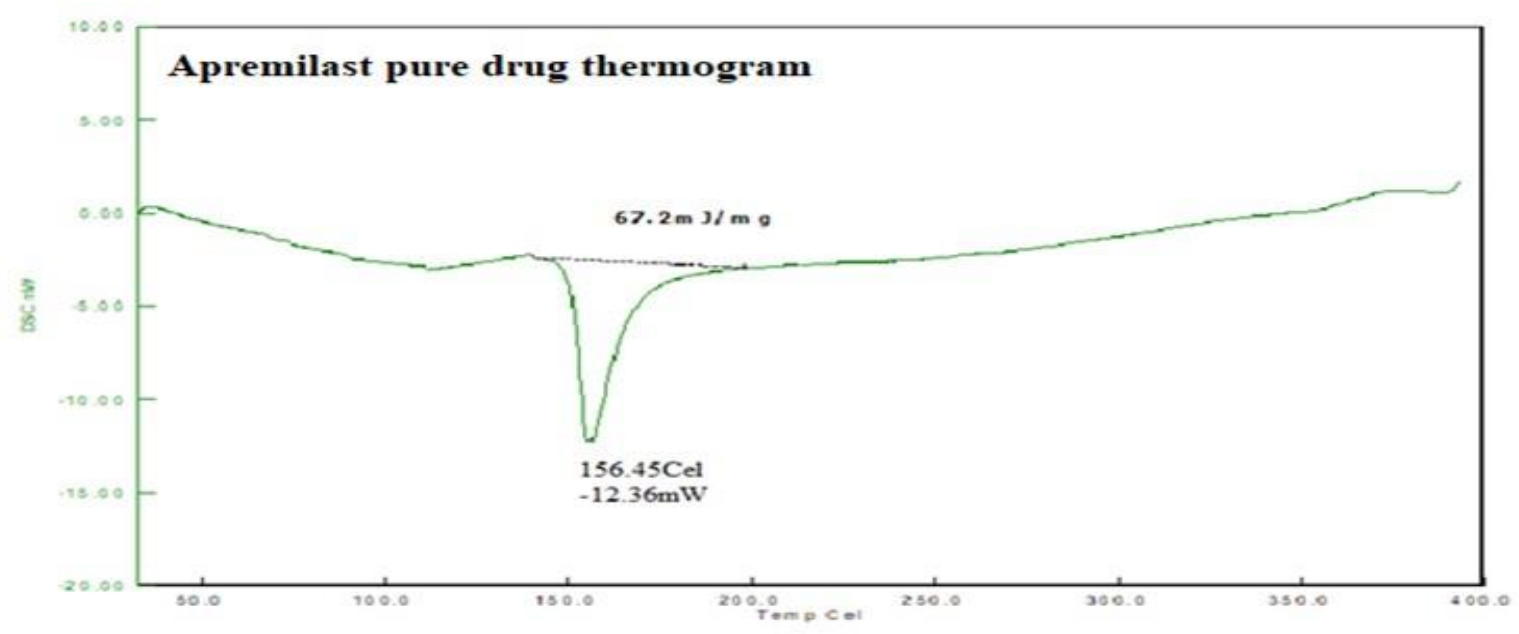

Figure 1: Differential Scanning Calorimetry of Pure Apremilast

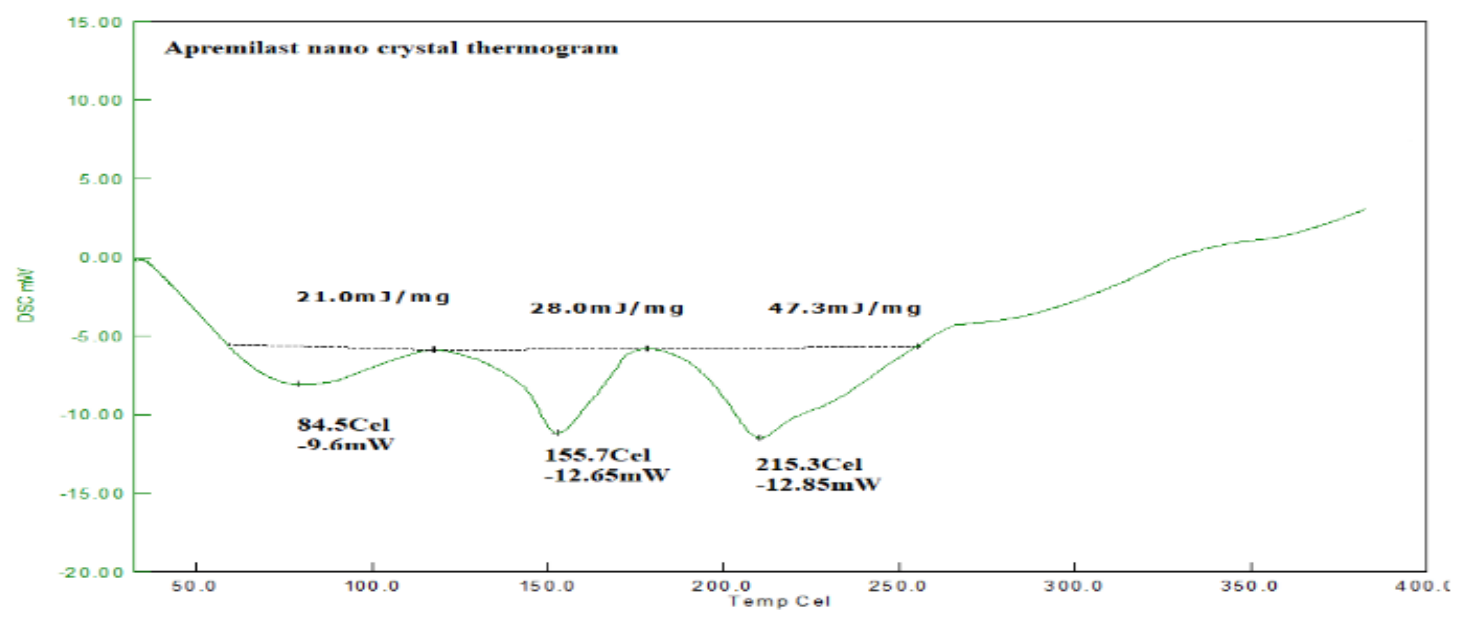

Figure 2: Differential Scanning Calorimetry of Apremilast Cocrystals

\section{FTIR spectroscopy study}

FTIR is an important medium used for the conformation of cocrystals formation and it showed the formation of hydrogen bond between pure drug and conformer. FTIR peak for pure APR and APR cocrystals was recorded and shown in Figs. 3 and 4. The principle bands were identified and significant changes were recorded. The pure APR spectra of IR showed the characteristics peak which was recorded at $2944 \mathrm{~cm}-1-\mathrm{NH}$ stretching, $1763 \mathrm{~cm}-1$ aromatic $-\mathrm{C}=\mathrm{O}$ ketone stretching, $1617 \mathrm{~cm}-1-\mathrm{C}=\mathrm{O}$ amide stretching, and $2944 \mathrm{~cm}-1 \mathrm{C}-\mathrm{H}$ stretching. The IR spectra of the APR cocrystals were showed the peak at $2578 \mathrm{~cm}-1$, $1704 \mathrm{~cm}-1,1519 \mathrm{~cm}-1$, and $3363 \mathrm{~cm}-1$ for $\mathrm{C}-\mathrm{H},-\mathrm{NH}, \mathrm{C}=\mathrm{O}$ ketone, and $\mathrm{C}=\mathrm{O}$ amide, respectively. The change in peak shape, peak intensities, and peak broadening was observed which indicates the formation and confirmation of the APR cocrystal with a new crystalline phase.

\section{Saturated solubility study}

Saturated solubility $(\mu \mathrm{g} / \mathrm{ml})$ of pure APR and APR cocrystals was performed successfully. The solubility of pure APR was found to be $6.89 \mu \mathrm{g} / \mathrm{ml}$ and the corystals was found to be 11.02. It clearly stated that the solubility of APR was increased in the cocrystal form of drug. The solubility of cocrystals was increased due to molecular interaction of non-covalent bonds and hydrogen bond formation between drug APR and conformer urea.

\section{In vitro dissolution study}

In vitro dissolution (\%) study of pure APR and APR cocrystals were carried out successfully. The dissolution curve of pure APR and an APR cocrystal in $6.8 \mathrm{pH}$ phosphate buffer is shown in Figure 5; it was an evident that the cocrystals of APR with urea clearly showed the improvement in dissolution rate as compared to pure drug.

\section{Evaluation of APR cocrystals loaded gel}

\section{Physical appearance}

The formulated APR cocrystals loaded gels were inspected visually. The gel was found to be white in color and smooth appearance.

\section{Viscosity and $\mathrm{pH}$}

The viscosity and $\mathrm{pH}$ of all formulations were determined successfully. The obtained data were given in Table 2 . 


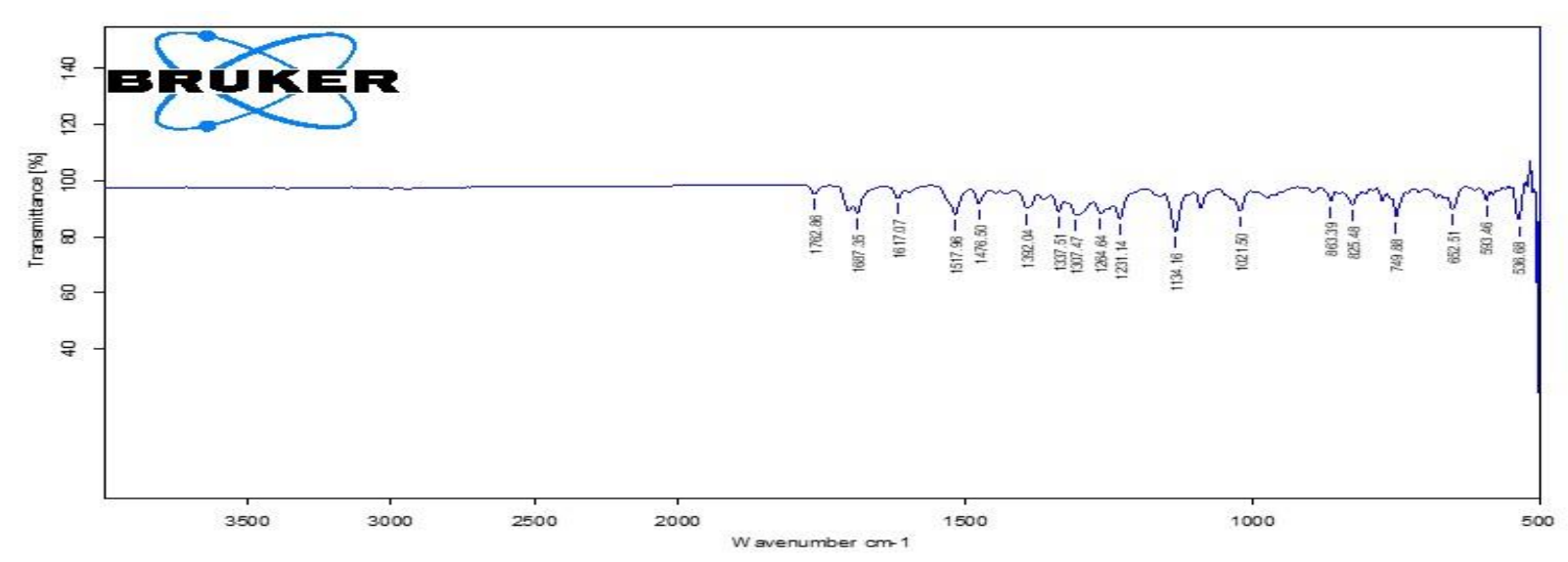

Figure 3: FTIR Spectra of Apremilast Pure Drug

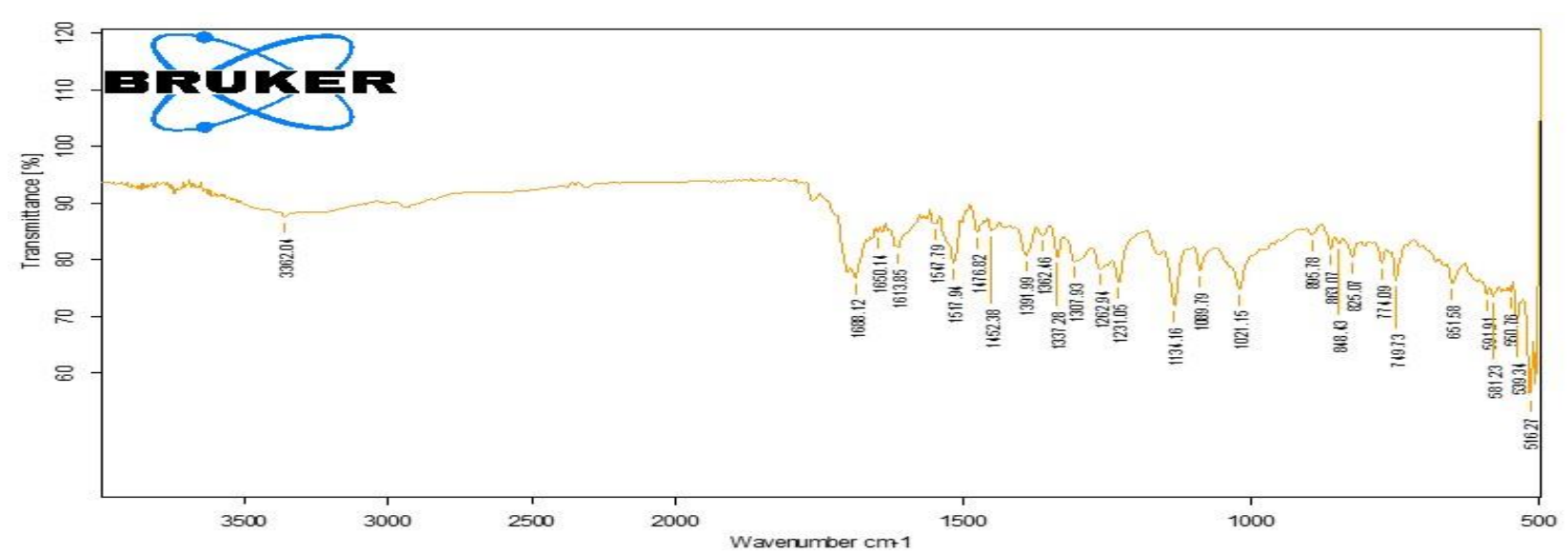

Figure 4: FTIR Spectra of Apremilast Cocrystals

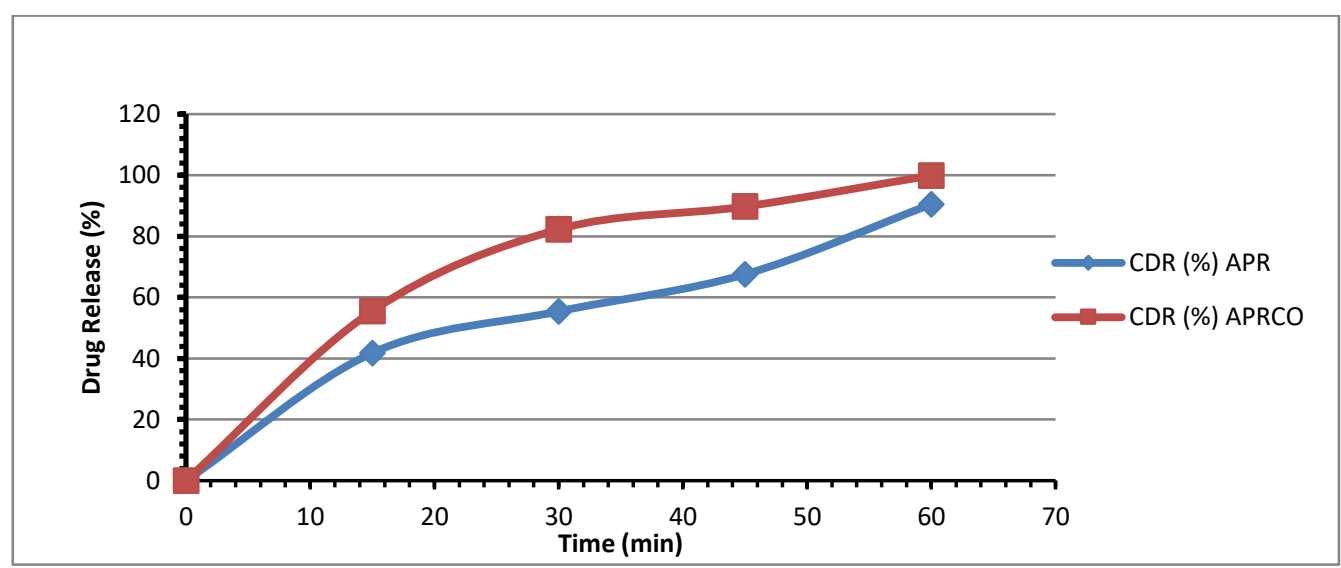

Figure 5: In-vitro dissolution of APR and APR Cocrystals

\section{Spreadability $(\mathrm{cm})$}

The spreadability of all the gels was ranging from $4.3 \mathrm{~cm}$ to $6.4 \mathrm{~cm}$. It was observed that formulations F1, F2, and F5 showed higher spreadability, which may be due to an increased concentration of carbopol 940. The spreadability test results are interpreted in Table 2.

\section{In vitro drug release (\%)}

From the drug release study, it was observed that formulations F1, F2, F5, and F6 showed the drug release from 65.4 to 98.9 up to 1 hour. This might be due to the increase in the concentration of carbopol 940 from 0.5 to $1.25 \%$ along with increase in the amount of HPMC added. The gel F3 and F4 showed drug release of 83.02 and 89.5 up to 1 hour which may be due to the fact that increased concentration of carbopol 940 was led to increasing the viscosity of these formulations which in turn makes the diffusion of drug through the dialysis membrane slower. Among all the six gels formulated, formulation F2 containing $1.25 \%$ of carbopol 940 and $1.25 \%$ of HPMC showed highest drug release of $98.9 \%$ and was optimized as the best. The drug release profile of apremilast gels is depicted in Table 3 and Figure 6. 
Table 2: Result of Viscosity, $\mathrm{pH}$ and Spreadability of different formulations

\begin{tabular}{|c|c|c|c|}
\hline Formulation Code & Viscosity $\mathbf{( c p s )}$ & $\mathbf{p H}$ & Spread ability $\mathbf{( c m})$ \\
\hline F1 & 569.7 & 6.7 & 5.5 \\
\hline F2 & 592.2 & 7.0 & 6.4 \\
\hline F3 & 390.2 & 6.4 & 4.3 \\
\hline F4 & 436.4 & 6.5 & 5.3 \\
\hline F5 & 552.6 & 6.7 & 5.4 \\
\hline F6 & 511.6 & 6.5 & 5.1 \\
\hline
\end{tabular}

Table 3: Percentage Drug release of Apremilast gels

\begin{tabular}{|c|c|c|c|c|c|c|}
\hline Time & F1 & F2 & F3 & F4 & F5 & F6 \\
\hline 0 & 0 & 0 & 0 & 0 & 0 & 0 \\
\hline 15 & 65.4 & 77.2 & 60.5 & 67.05 & 72.5 & 70.06 \\
\hline 30 & 72.6 & 85 & 72.3 & 69.08 & 77.89 & 76.05 \\
\hline 60 & 88.6 & 88.5 & 78.6 & 77.5 & 88.06 & 88.15 \\
\hline
\end{tabular}

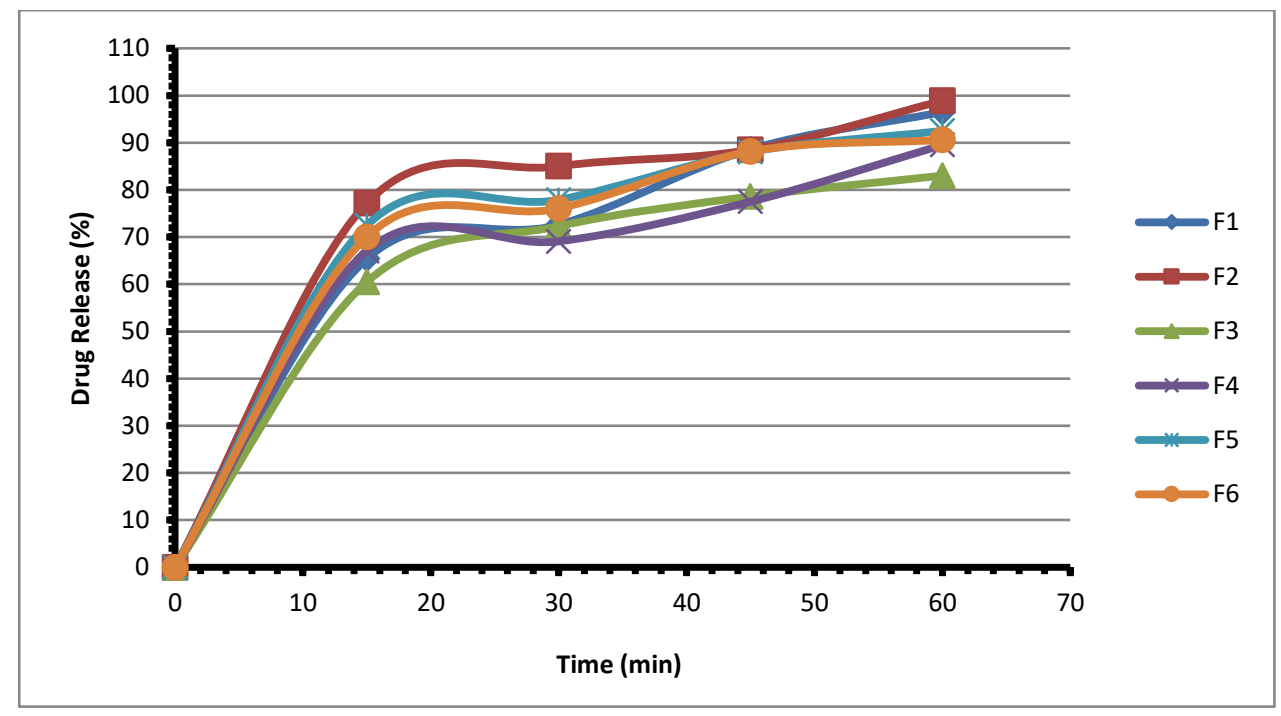

Figure 6: Drug Release of Apremilast Gel

\section{Stability study}

During the storage of APR cocrystals loaded gel, there may be chances of changes in the physicochemical parameters. Hence, the prepared formulations were subjected for the stability study at room temperature and accelerated condition for a period of 1 month to define the stability. It was found that the APR loaded gel was stable at both conditions. The obtained data were given in Table 4.

Table 4: Result of Stability Study

\begin{tabular}{|c|c|c|}
\hline Month & $\mathbf{0}$ & $\mathbf{1}$ \\
\hline $\begin{array}{c}\text { Room temp } \\
(25 \% \mathrm{C}, 60 \% \% \mathrm{RH})\end{array}$ & $100 \%$ & $100 \%$ \\
\hline $\begin{array}{c}\text { Accelerated temp } \\
(40 \% \mathrm{C}, \mathrm{RH} 75 \%)\end{array}$ & $100 \%$ & $99.21 \%$ \\
\hline
\end{tabular}

\section{CONCLUSION}

The Cocrystals of APR and Urea were prepared using the solvent evaporation technique. The prepared APRcocrystals exhibit good physicochemical properties such as solubility and dissolution. The prepared APR-cocrystals were formulated into a topical gel. Carbapol-940 and HPMC were used as a gelling agent as independent variables. F2 formulation was found to be optimized batch and selected variables show a significant effect on the responses that are drug release and spreadability.

From the overall conducted study, we can conclude that the newly developed crystalline form of APR with Urea showed increased solubility and dissolution rate and it was given in topical formulation to overcome problems related to oral administration of drug. 
Acknowledgments: The authors are sincere thankful to principal and management of Anwarul Uloom College Pharmacy, New Mallepally, Hyderabad.

\section{REFERENCES}

1. Dubertret L, Mrowietz U, Ranki A, and the EUROPSO Patient Survey Group. European patient perspectives on the impact of psoriasis: the EUROPSO patient membership survey. Br J Dermatol 2006; 155: 729-36.

2. Griffi ths CEM, Barker JNWN. Pathogenesis and clinical features of psoriasis. Lancet 2007; 370: 263-71

3. Nestle FO, Kaplan DH, Barker J. Psoriasis. N Engl J Med 2009; 361: 496-509.

4. Mason AR, Mason JM, Cork MJ, Hancock H, Dooley G. Topical treatments for chronic plaque psoriasis of the scalp: a systematic review. Br J Dermatol 2013; 169: 519-27

5. Hägg D, Eriksson $M$, Sundström A, Schmitt-Egenolf $M$. The higher proportion of men with psoriasis treated with biologics may be explained by more severe disease in men. PLoS One 2013; 8: e63619.

6. Shmidt E, Wetter DA, Ferguson SB, Pittelkow MR. Psoriasis and palmoplantar pustulosis associated with tumor necrosis factor- $\alpha$ inhibitors: the Mayo Clinic experience, 1998 to 2010. J Am Acad Dermatol 2012; 67: e179-85.

7. Fong SYK, Ibisogly A, Bauer-Brandl A. Solubility enhancement of BCS class-II drug by solid phospholipid dispersions: Spray drying versus freeze-drying. Int J Pharm 2015; 496: 382-91.

8. Jones W, Motherwell WDS, Trask AV. Pharmaceutical cocrystals: An Emerging approach to physical property enhancement. MRS Bull 2006; 31: 875-879.
9. Zaworotko M. Crystal engineering of co-crystals and their relevance to pharmaceuticals and solid-state chemistry. Acta Cryst 2008; 64: 11-12.

10. Otezla [package insert]. Summit, NJ: Celgene Corporation; 2014.

11. Sevukarajan M., Thanuja B, Sodanapalli R, Nair R. Synthesis and characterization of pharmaceutical co-crystal: Aceclofenac: Nicotinamide. J Pharm Sci Res 2011; 3: 128893.

12. Payghan SA. Preparation and characterization of molecular complexes of finofibrate co-crystal. Asian J Pharm 2017; 11: 745-58.

13. Panzade $P$, Shendarkar $G$. Design and preparation of zaltoprofen-nicotinamide pharmaceutical co-crystal via liquid assisted grinding method. Indian J Pharm Educ 2019; 53: S563-70.

14. Sai Priyanka NV, Neeraja $P$, Mangilal T, Kumar MR. Formulation and evaluation of gel loaded with microspheres of aprimilast for transdermal delivery system. Asian J Pharm Clin Res 2019; 12: 411-7.

15. Sopyan I, Fudholi A, Muchtaridi M, Sari IP. Simvastatinnicotinamide co-crystal: Design, preparation and preliminary characterization. Trop J Pharm Res 2017; 16: 297-303.

16. Sopyan I, Fudholi A, Muchtaridi M, Sari IP. Cocrystalization: A tool to enhance the solubility and dissolution rate of simvastatin. J Young Pharm 2017; 9: 1836.

Source of Support: The author(s) received no financial support for the research, authorship, and/or publication of this article.

Conflict of Interest: The author(s) declared no potential conflicts of interest with respect to the research, authorship, and/or publication of this article.

For any question relates to this article, please reach us at: globalresearchonline@rediffmail.com New manuscripts for publication can be submitted at: submit@globalresearchonline.net and submit_ijpsrr@rediffmail.com 